\title{
Erratum to: Managing the genomic revolution in cancer diagnostics
}

\author{
Doreen Nguyen $^{1} \cdot$ Christopher D. Gocke $e^{1,2,3}$
}

Published online: 1 August 2017

(C) Springer-Verlag GmbH Deutschland 2017

Erratum to: Virchows Arch

DOI 10.1007/s00428-017-2175-2

The above article originally published with incorrect alignment present in Table 2. The table has now been corrected within the article, and can also be found below.

The online version of the original article can be found at http://dx.doi.org/ $10.1007 /$ s00428-017-2175-2

Christopher D. Gocke

cgocke1@jhmi.edu

1 The Department of Pathology, Johns Hopkins University, Baltimore, MD 21287, USA

2 The Department of Oncology, Johns Hopkins University, Baltimore, MD 21287, USA

3 Johns Hopkins Genomics, Johns Hopkins University School of Medicine, 1812 Ashland Ave, Suite 200, Baltimore, MD 21205, USA 


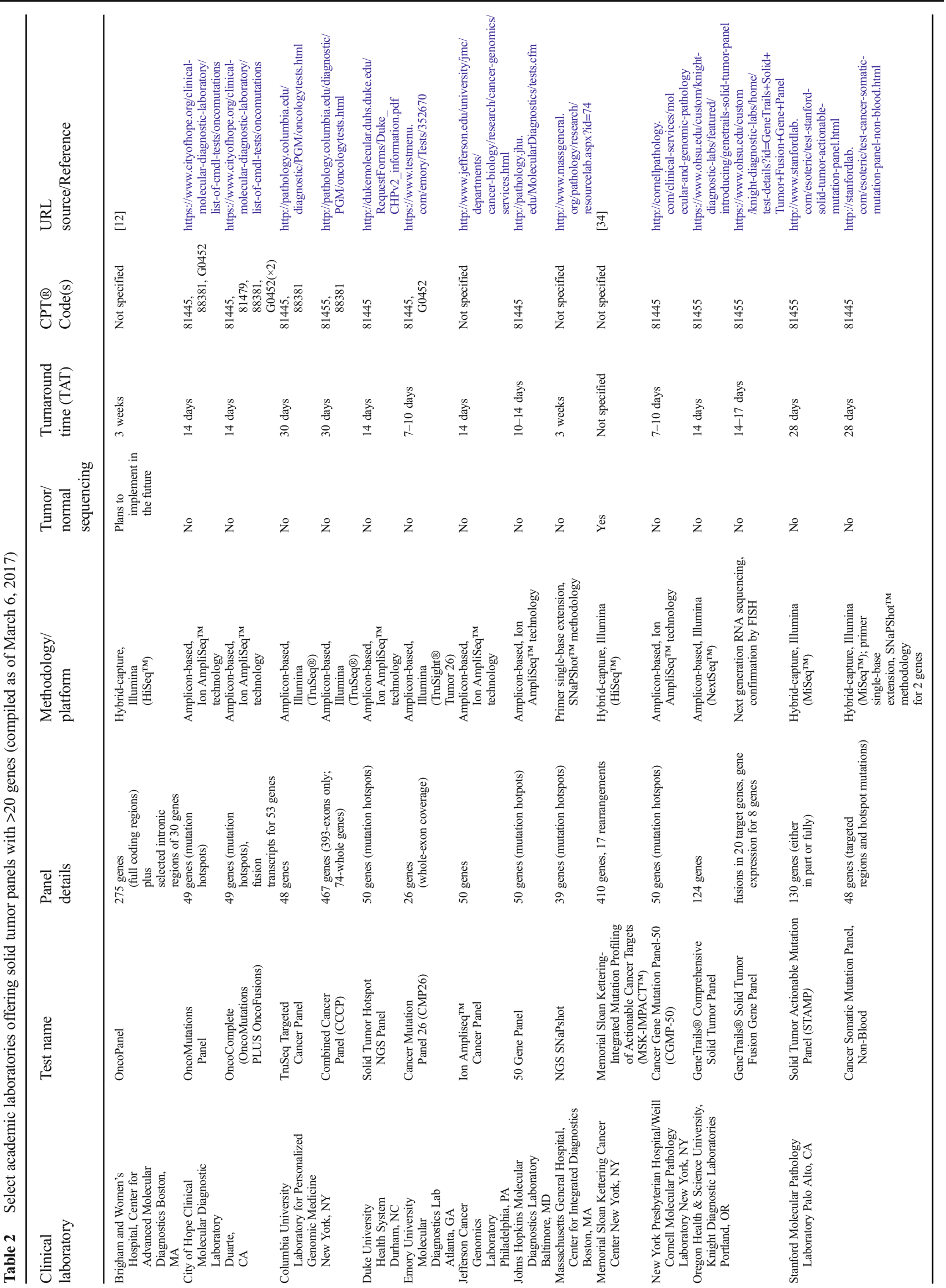




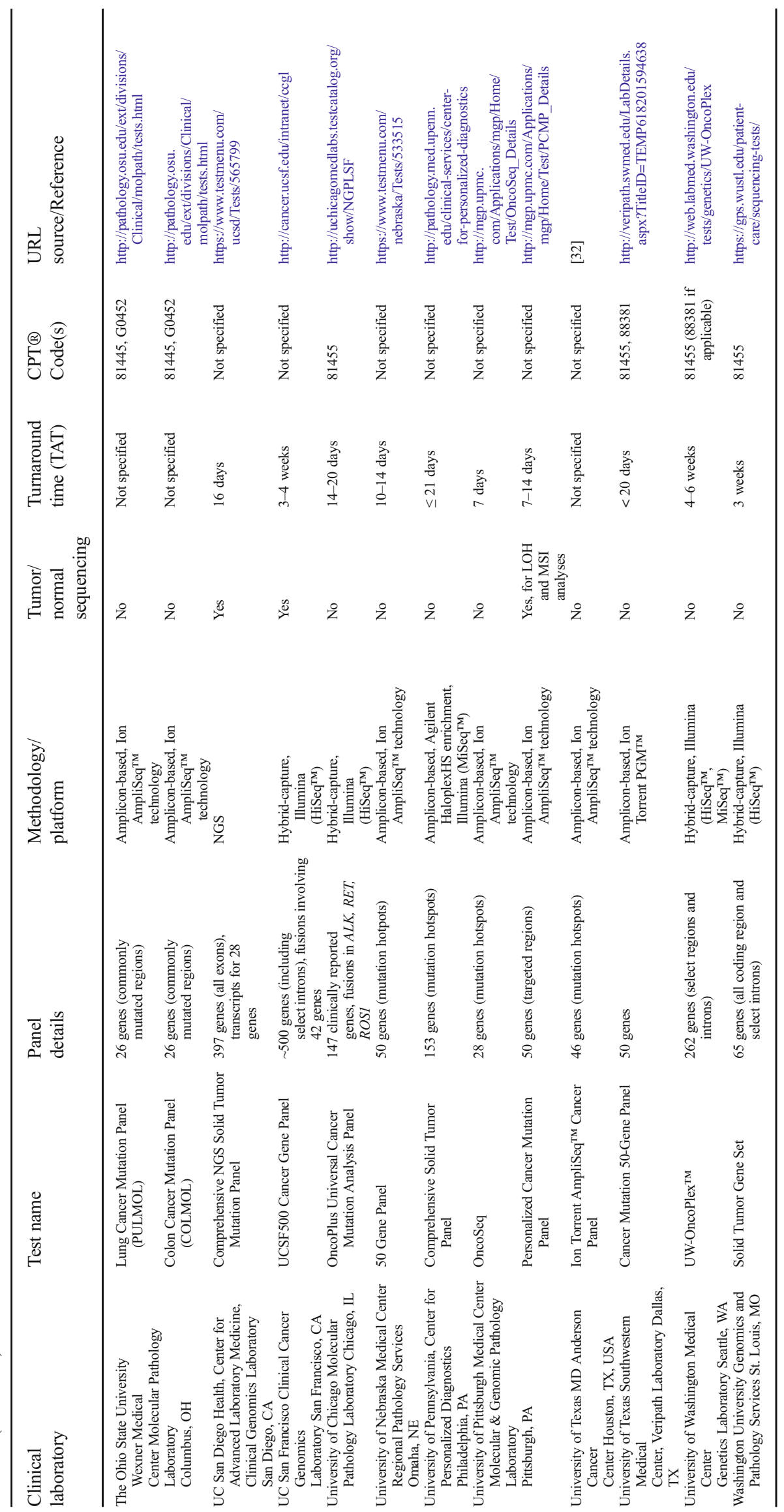

